\title{
Cigarette smoking and cardio-renal events in patients with atherosclerotic renal artery stenosis
}

\section{Citation}

Drummond, C. A., P. S. Brewster, W. He, K. Ren, Y. Xie, K. R. Tuttle, S. T. Haller, et al. 2017. "Cigarette smoking and cardio-renal events in patients with atherosclerotic renal artery stenosis." PLoS ONE 12 (3): e0173562. doi:10.1371/journal.pone.0173562. http:// dx.doi.org/10.1371/journal.pone.0173562.

\section{Published Version}

doi:10.1371/journal.pone.0173562

\section{Permanent link}

http://nrs.harvard.edu/urn-3:HUL.InstRepos:32072004

\section{Terms of Use}

This article was downloaded from Harvard University's DASH repository, and is made available under the terms and conditions applicable to Other Posted Material, as set forth at http:// nrs.harvard.edu/urn-3:HUL.InstRepos:dash.current.terms-of-use\#LAA

\section{Share Your Story}

The Harvard community has made this article openly available.

Please share how this access benefits you. Submit a story.

\section{Accessibility}




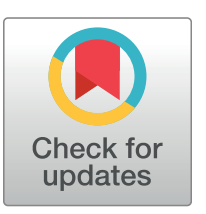

\section{OPENACCESS}

Citation: Drummond CA, Brewster PS, He W, Ren K, Xie Y, Tuttle KR, et al. (2017) Cigarette smoking and cardio-renal events in patients with atherosclerotic renal artery stenosis. PLOS ONE 12 (3): e0173562. https://doi.org/10.1371/journal. pone.0173562

Editor: Christophe Mariat, University Jean MONNET of SAINT-ETIENNE, UNITED STATES

Received: September 15, 2016

Accepted: February 22, 2017

Published: March 17, 2017

Copyright: @ 2017 Drummond et al. This is an open access article distributed under the terms of the Creative Commons Attribution License, which permits unrestricted use, distribution, and reproduction in any medium, provided the original author and source are credited.

Data Availability Statement: All relevant data have been provided in the manuscript.

Funding: This work was supported by the National Institutes of Health [Grant Numbers: U01HL072734, U01HL072735, U01HL072736, U01HL072737, 5U01HL071556, R01-HL-105649, R01-HL-109015, and F32DK104615-01]. The National and Ohio Valley Affiliate of the American Heart Association (13POST16860035). The content is solely the responsibility of the authors and does not necessarily represent the official views of the
RESEARCH ARTICLE

\section{Cigarette smoking and cardio-renal events in patients with atherosclerotic renal artery stenosis}

Christopher A. Drummond ${ }^{1 \odot}$, Pamela S. Brewster ${ }^{1 \odot}$, Wencan $\mathrm{He}^{2}, \mathrm{Kaili} \mathrm{Ren}^{2}, \mathrm{Yanmei} \mathrm{Xie}^{2}$, Katherine R. Tuttle ${ }^{3}$, Steven T. Haller ${ }^{1}$, Kenneth Jamerson ${ }^{4}$, Lance D. Dworkin ${ }^{1}$, Donald E. Cutlip ${ }^{5}$, Timothy P. Murphy ${ }^{6}$, Ralph B. D'Agostino, Sr. ${ }^{5}$, William L. Henrich ${ }^{7}$, Jiang $\operatorname{Tian}^{1 *}$, Joseph I. Shapiro ${ }^{8}$, Christopher J. Cooper ${ }^{1}$

1 Department of Medicine, University of Toledo College of Medicine and Life Sciences, Toledo, $\mathrm{OH}$, United States of America, 2 Department of Mathematics, University of Toledo, Toledo, OH, United States of America, 3 Division of Nephrology, University of Washington School of Medicine, Providence Health Care, Spokane, WA, United States of America, 4 Department of Medicine, University of Michigan, Ann Arbor, MI, United States of America, 5 Harvard Clinical Research Institute, Boston, MA, United States of America, 6 Departments of Medicine and Diagnostic Imaging, Rhode Island Hospital and Alpert Medical School of Brown University, Providence, RI, United States of America, 7 University of Texas Health Science Center, San Antonio TX, United States of America, 8 Joan C. Edwards School of Medicine, Marshall University, Huntington, WV, United States of America

จ These authors contributed equally to this work.

* Jiang.tian@utoledo.edu

\section{Abstract}

Cigarette smoking causes cardiovascular disease and is associated with poor kidney function in individuals with diabetes mellitus and primary kidney diseases. However, the association of smoking on patients with atherosclerotic renal artery stenosis has not been studied. The current study utilized data from the Cardiovascular Outcomes in Renal Atherosclerotic Lesions (CORAL, NCT00081731) clinical trial to evaluate the effects of smoking on the risk of cardio-renal events and kidney function in this population. Baseline data showed that smokers ( $n=277$ out of 931 ) were significantly younger at enrollment than non-smokers $(63.3 \pm 9.1$ years vs $72.4 \pm 7.8$ years; $p<0.001)$. In addition, patients who smoke were also more likely to have bilateral renal artery stenoses and peripheral vascular disease (PVD). Longitudinal analysis showed that smokers experienced composite endpoint events (defined as first occurrence of: stroke; cardiovascular or renal death; myocardial infarction; hospitalization for congestive heart failure; permanent renal replacement; and progressive renal insufficiency defined as $30 \%$ reduction of GFR from baseline sustained for $\geq 60$ days) at a substantially younger age compared to non-smokers $(67.1 \pm 9.0$ versus $76.1 \pm 7.9, p<0.001)$. Using linear regression and generalized linear modeling analysis controlled by age, sex, and ethnicity, smokers had significantly higher cystatin C levels $(1.3 \pm 0.7$ vs $1.2 \pm 0.9, p<0.01)$ whereas creatinine and estimated glomerular filtration rate (eGFR) were not different from non-smokers. From these data we conclude that smoking has a significant association with deleterious cardio-renal outcomes in patients with renovascular hypertension. 
National Institutes of Health. Drugs for this study were provided by AstraZeneca, device support was provided by Cordis Corporation and supplemental financial support was granted by both Cordis Corporation and Pfizer Inc.

Competing interests: The authors have declared that no competing interests exist.

\section{Introduction}

Despite tobacco control programs aimed at reducing consumption, cigarette smoking still causes 443,000 deaths each year in the United States according to the Centers for Disease Control and Prevention [1, 2]. Cigarette smoking is widely known to have adverse health effects on cardiovascular disease, chronic obstructive lung disease, liver disease and cancer [3-5], and may have adverse effects on kidney function [6]. The deleterious effects of smoking on kidney function have been reported in patients with diabetes mellitus and primary kidney diseases including polycystic kidney disease, glomerulonephritis and lupus nephritis[3-9]. Recently, epidemiologic studies demonstrated that smoking increases the risk of chronic kidney disease progression and kidney failure in patients with diabetes and hypertension [10, 11]. However, the importance of active smoking in patients with renal artery stenosis has not been described.

Renal artery stenosis (RAS) is a common problem and is present in roughly $1-5 \%$ of the 60 million Americans with hypertension [12-14]. This is considered a disease of older persons with most studies having a mean age for RAS greater than 70 years [15]. Low kidney function is common and there is a strikingly high rate of adverse cardiovascular events and mortality [16]. Smoking is a known risk factor for atherosclerosis, and a smoking history is typical in patients with renal artery stenosis [17]. However, the association between smoking and cardio-renal outcomes has not been studied in patients with atherosclerotic renal disease. This study used data from the Cardiovascular Outcomes in Renal Atherosclerotic Lesions (CORAL, NCT00081731) [18] clinical trial to evaluate changes in cardio-renal outcomes and secondary parameters in RAS patients who are active smokers.

\section{Materials and methods}

\section{Study population}

CORAL is a prospective, international, multicenter clinical trial that randomly assigned 931 participants with atherosclerotic renal artery stenosis who received optimal medical therapy to stenting versus no stenting from May 2005 through January 2010. The detailed description and analysis of the endpoints have previously been described [18]. For the current study the primary outcome was the composite endpoint defined as the first occurrence of any secondary endpoints (cardiovascular or renal death; myocardial infarction (ST segment elevation or silent $\mathrm{MI})$; stroke; congestive heart failure (CHF); progressive renal insufficiency ( $\geq 30 \%$ decline in GFR over the period of 6 months [19]); and permanent renal replacement. Active cigarette smoking was defined as tobacco use within the year prior to enrollment in the study. The study was approved by the Institutional Review Board at the University of Toledo (IRB104827). All of the centers followed the institutional and study guidelines. All participating patients have provided written informed consent. Detailed study entry criteria have been published [18]. Patients with renal artery stenosis of at least $60 \%$ were eligible if they had hypertension while receiving two or more antihypertensive agents or had an estimated glomerular filtration rate (eGFR) less than $60 \mathrm{ml} / \mathrm{minute} / 1.73 \mathrm{~m}^{2}$ [18]. Angiograms were analyzed for verification of stenosis by the Angiography Core Lab for the study at the University of Virginia [18].

\section{Statistical analysis}

Study data are presented as continuous (mean \pm Standard Deviation [SD]), categorical (number and percentage), and medians (with interquartile range [IQR]). Comparisons of continuous data were evaluated with ANOVA and two-sample $t$ tests, while for categorical variables, the Fisher exact test was used and odds ratios (OR) were calculated. Statistical significance was 
defined as a p-value $<0.05$. Data was tested for normal distribution using the Shapiro-Wilk test and nonparametric Mann-Whitney $\mathrm{U}$ rank test was used if the assumption of normality was violated. Where possible, the data was log-transformed to approximate a normal distribution and parametric analysis was undertaken. All analyses were performed using R software (version 3.0.0) and SAS (version 9.3).

\section{Multiple variable models and longitudinal analyses}

Univariate analysis was performed comparing smokers to non-smokers on baseline characteristics, and variables with $\mathrm{p}<0.05$ were included in multiple variable analyses using multiple linear regression model and generalized linear model (GLM) with application of stepwise model selection. Each of the baseline factors were analyzed as response variables adjusted for age and smoking status to correct for potential age bias and to guide in the selection of factors for the multivariable models. All multiple variable analyses were controlled for age, sex, ethnicity (Hispanic/Latino) and body mass index (BMI, weight in kilograms divided by the square of the height in meters). Longitudinal analyses using linear mixed effect model were performed using time (continuous) as the random coefficient to assess the effects of smoking on measures of kidney function (eGFR, cystatin C, serum creatinine concentrations) and damage (urine albumin-to-creatinine ratio [UACR]) up to 5 years. The models were checked using two versions of the mixed effect model: one version contained both time as a random coefficient effect and fixed effects, while the other version considered time as a fixed event. ANOVA was used to compare the residual sums of squares for the 2 models. The random effect model was selected as it yielded lower AIC and BIC measures.

\section{Event analysis}

Due to the age discrepancy between smokers and non-smokers, we selected age-at-event as the time-scale for hazard risk since the covariate of interest (smoking) is not independent of age and the Cox model using time-to-event may incur bias even when adjusting for age [20-23]. Moreover, smokers accrue risk over their lifetime that would not be reflected if time-to-events were used as the response. Age-at-event outcomes were expressed using Kaplan-Meier estimates with comparisons between smoking status groups using the logrank statistic. Hazard risk ratios were calculated using the Cox proportional-hazards model, and the comparison between smoking groups was evaluated using both survival time and age-at-event as the response variables. Model diagnostics were performed using the CoxSnell residual plot test to check for goodness of fit. The proportional hazards assumption tests from the R function cox.zph in the survival package for all the survival models had $\mathrm{p}$ values $>0.05$ indicating that the null hypothesis of proportional hazards was not rejected. The extended Cox model was used to test for interaction among model predictors and time. The time-dependent covariates were generated by building interactions of the predictors and a function of survival age (age-to-event), and were included in the models. The p-values for all time-covariate interactions in all of the survival models were greater than 0.05 , confirming the null hypothesis assumption of proportional hazards, and indicating that the fitted Cox regression hazard models are adequate. The predicted probability of the binary occurrence of the composite endpoint or any of the secondary endpoint events was calculated using receiver operating characteristic (ROC) for logistic regression with adjustment for age, sex, ethnicity and BMI. 


\section{Results}

\section{Baseline characteristics comparison of smokers and non-smokers}

The CONSORT flow diagram of CORAL study is shown in Fig 1. There were 277 (30\%) smokers among the 931 participants in the CORAL trial. The median follow-up period was 43 months (interquartile range of 31 to 55 ). Smokers were younger than non-smoking participants at enrollment $(63.3 \pm 9.1$ years old versus $72.4 \pm 7.8$ years old, $\mathrm{p}<0.001$; Fig 2$)$. Other baseline characteristics shown in Table 1 demonstrate no difference in renal artery stenosis severity between groups based on degree of stenosis $(68.8 \pm 11.3 \%$ versus $68.5 \pm 11.7 \%, \mathrm{p}=0.68$. Participants who smoke tended to be taller $(66.4 \pm 4.2$ inches versus $65.7 \pm 3.9$ inches, $\mathrm{p}<0.001)$, leaner $(172.3 \pm 37.1 \mathrm{lbs}$ versus $176.9 \pm 36.2 \mathrm{lbs}, \mathrm{p}=0.087)$ and had a significantly lower BMI $(28.3 \pm 5.6$ versus $29.7 \pm 5.6, \mathrm{p}<0.001)$. Smokers were more likely to be on anti-platelet medication $(75 \%$ versus $65 \%, \mathrm{p}=0.012)$, and were on fewer hypertensive drugs $(1.8 \pm 1.5$ versus 2.1 $\pm 1.5, \mathrm{p}=0.015)$. In generalized linear models controlling for age, sex, ethnicity and BMI (Table 2), it was found that smokers were more likely to have peripheral vascular disease $(\mathrm{p}<0.001)$ and bilateral renal artery stenosis $(\mathrm{p}<0.05)$. The rate of diabetes amongst smokers was significantly lower than in non-smokers $(\mathrm{p}<0.001)$ which may be attributable to their younger age and leaner weight.

\section{Smoking as a risk factor for cardio-renal events in patients with renal artery stenosis}

In order to determine whether smoking is associated with the composite endpoint in these patients, event-free survival was plotted against age (Fig 3). Subjects were followed over a

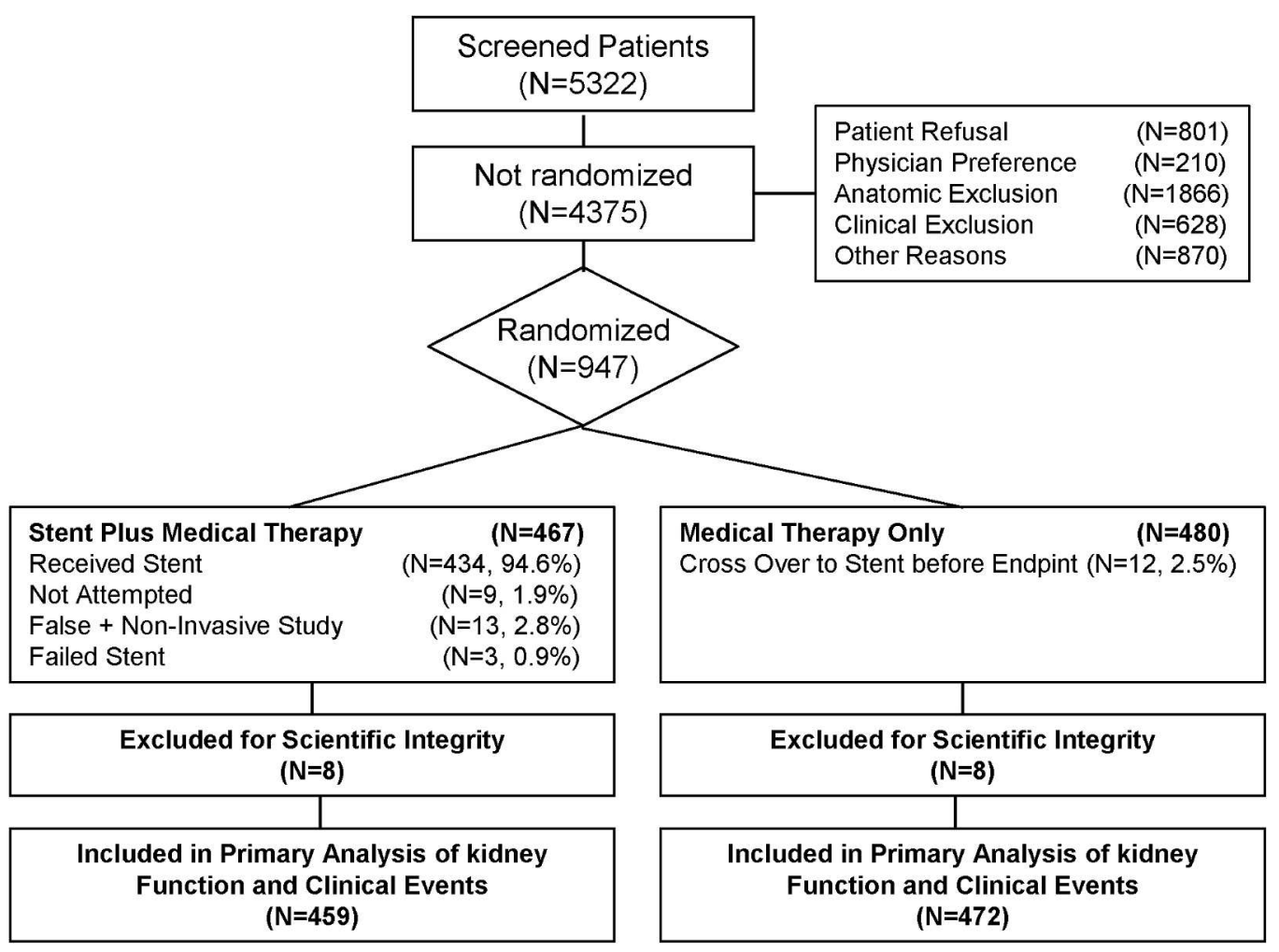

Fig 1. CONSORT flow diagram of CORAL study.

https://doi.org/10.1371/journal.pone.0173562.g001 


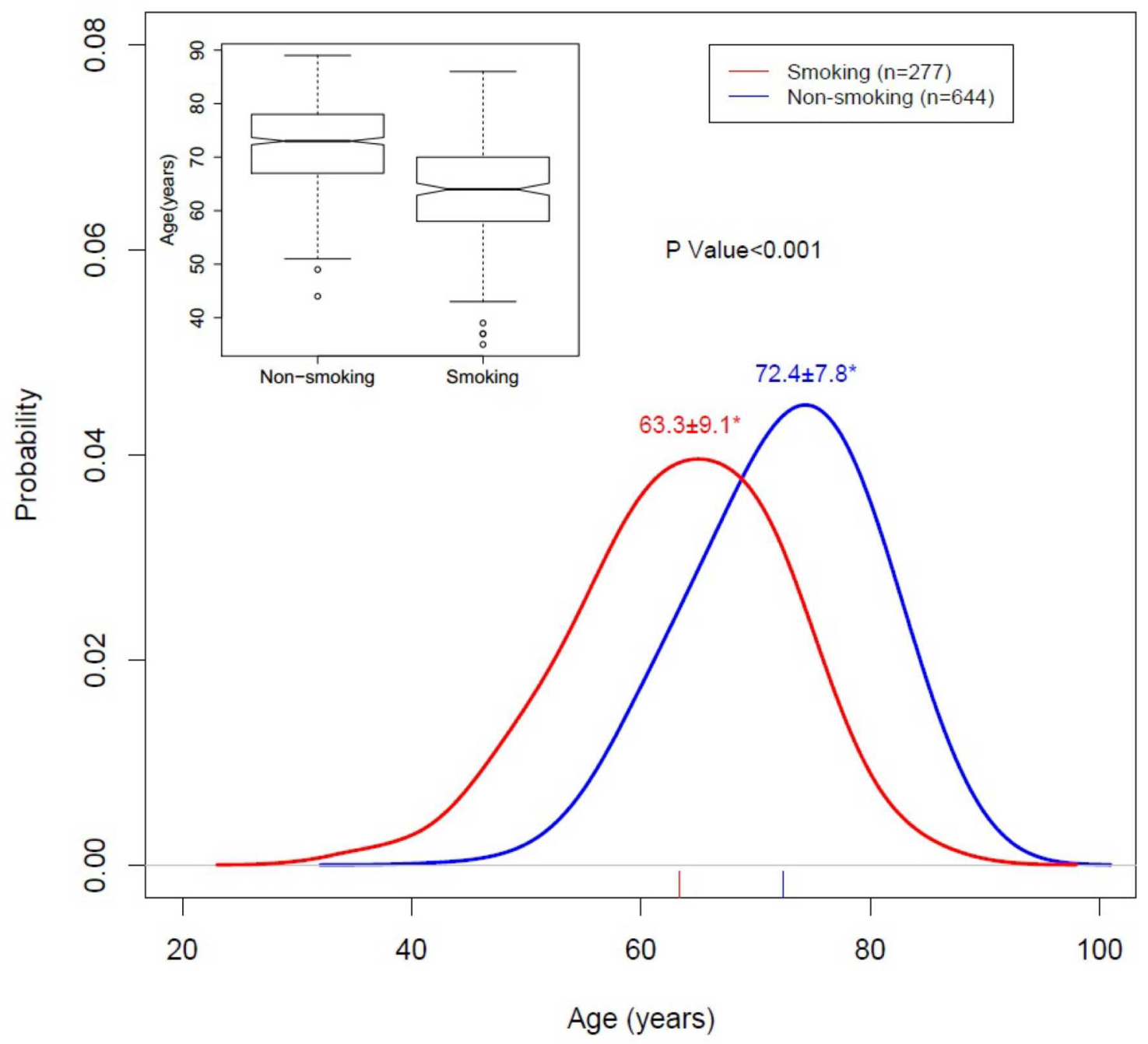

Fig 2. Age in years for smokers and non-smokers at study enrollment. The Red curve represents the distribution of age for smokers $(\mathrm{N}=277)$ and the blue curve represents age at study enrollment for non-smokers $(\mathrm{N}=644)$. Numbers at the peak of the distribution curves are the mean years of age at study enrollment \pm SD for the patient populations as defined above. The insert boxplot shows age with interquartile ranges and $95 \%$ confidence intervals differentiated by smoking status. The asterisk $(*)$ indicates that the means are significantly different $(p<0.001)$ as determined by two-sample t-test.

https://doi.org/10.1371/journal.pone.0173562.g002

median follow-up of 43 months (IQR, 31 to 55). Smokers experienced these clinical events at a significantly younger age than non-smokers. Using age-at-event to determine Cox-proportional hazard ratios, participants who smoke were $2.32(1.79,2.98 ; \mathrm{p}<0.001)$ times more likely to have a primary composite endpoint event at a younger age $(67.1 \pm 9.0$ vs $76.1 \pm 7.9, \mathrm{p}<0.001)$ (Table 3 and Fig 3). Additionally, smokers were more likely to experience myocardial infarction $(1.82[1.06,3.13] ; \mathrm{p}=0.03)(68 \pm 9.1$ vs $77 \pm 7.8, \mathrm{p}<0.001)$, stroke $(2.59$ [1.27, 5.27]; $\mathrm{p}=0.01)(68.9 \pm 9.1$ vs $77.1 \pm 7.8, \mathrm{p}<0.001)$, hospitalization for congestive heart failure $(2.03$ $[1.17,3.52] ; \mathrm{p}=0.01)(68 \pm 9.0$ vs $77 \pm 7.8, \mathrm{p}<0.001)$, progressive renal insufficiency $(2.38$ [1.68, 3.38 ]; $\mathrm{p}<0.001)(67.5 \pm 9.0$ vs $76.4 \pm 7.9, \mathrm{p}<0.001)$, and death due to cardiovascular or renal disease $(1.77[1.02,3.05] ; \mathrm{p}=0.04)(68.1 \pm 9.1$ vs $77.1 \pm 7.8, \mathrm{p}<0.001)$. The only secondary clinical end-point observed not to be significantly affected by smoking was permanent renal 
Table 1. Baseline clinical characteristics comparisons by smoking status within the last year.

\begin{tabular}{|c|c|c|c|}
\hline Baseline Characteristics* & Non-smoking $(n=654)$ & Smoking $(n=277)$ & P-value \\
\hline \multicolumn{4}{|l|}{ Demographic/physical examination } \\
\hline Age (yr) & $72.4 \pm 7.8$ & $63.3 \pm 9.1$ & $<0.001$ \\
\hline Male sex & $317(49)$ & 133(48) & 0.77 \\
\hline White race & $584(91)$ & 255(92) & 0.53 \\
\hline Hispanic/Latino & $39(6)$ & $15(5)$ & 0.76 \\
\hline United States as country origin & $534(83)$ & $233(84)$ & 0.70 \\
\hline Height (in) & $65.7 \pm 3.9$ & $66.4 \pm 4.2$ & $<0.01$ \\
\hline Weight (lb) & $176.9 \pm 36.2$ & $172.3 \pm 37.1$ & 0.087 \\
\hline BMI $\left(\mathrm{kg} / \mathrm{m}^{2}\right)$ & $29.7 \pm 5.6$ & $28.3 \pm-5$. & $<0.001$ \\
\hline Systolic BP (mmHg) & $150.8 \pm 22.7$ & $148.4 \pm 24.2$ & 0.15 \\
\hline Diastolic BP (mmHg) & $77.9 \pm 12.9$ & $80.1 \pm 13.6$ & 0.021 \\
\hline Systolic BP at goal & $158(25)$ & $83(30)$ & 0.10 \\
\hline \multicolumn{4}{|l|}{ Laboratory values (assessed by core lab) } \\
\hline Creatinine $(\mathrm{mg} / \mathrm{dl})$ & $1.3 \pm 0.5$ & $1.2 \pm 0.5$ & 0.10 \\
\hline Cystatin C (mg/L) & $1.3 \pm 0.5$ & $1.3 \pm 0.5$ & 0.95 \\
\hline MDRD-eGFR (ml/min per $\left.1.73 \mathrm{~m}^{2}\right)$ & $59.6 \pm 22.4$ & $65.7 \pm 27.2$ & 0.002 \\
\hline CKD-EPI creatinine formula & $56.1 \pm 20.8$ & $63.3 \pm 24.5$ & $<0.001$ \\
\hline CKD-EPI cystatin C formula & $59.9 \pm 24.1$ & $62.1 \pm 24.9$ & 0.23 \\
\hline CKD-EPI Creatinine- cystatin C formula & $58.1 \pm 21.7$ & $62.8 \pm 25.8$ & $<0.01$ \\
\hline Potassium (mmol/L) & $4.2 \pm 0.6$ & $4.2 \pm 0.5$ & 0.33 \\
\hline Urine albumin creatinine ratio $(\mu \mathrm{g} / \mathrm{mg})$ & $217.1 \pm 700.7$ & $196.3 \pm 717.0$ & 0.7 \\
\hline Dipstick proteinuria $\geq 100$ mg/dl & $32(5)$ & 12(4) & 0.74 \\
\hline \multicolumn{4}{|l|}{ Angiographic findings } \\
\hline$\%$ stenosis, assessed by core laboratory & $68.5 \pm 11.7$ & $68.8 \pm 11.3$ & 0.68 \\
\hline$\%$ stenosis, assessed visually at site & $75.7 \pm 10.9$ & $76.7 \pm 10.5$ & 0.24 \\
\hline \multicolumn{4}{|l|}{ Risk factors/indications } \\
\hline Creatinine $\geq 1.6(\mathrm{mg} / \mathrm{dl})$ & $464(72)$ & $220(80)$ & 0.017 \\
\hline Peripheral vascular disease & $280(44)$ & $180(66)$ & $<0.001$ \\
\hline Hyperlipidemia & $579(90)$ & $236(88)$ & 0.24 \\
\hline Prior myocardial infarction & $173(27)$ & $86(31)$ & 0.26 \\
\hline Prior transient ischemic accident & $127(20)$ & $54(20)$ & 0.99 \\
\hline Angina & $69(12)$ & $34(14)$ & 0.49 \\
\hline Cardiovascular disease & $361(61)$ & $164(65)$ & 0.44 \\
\hline Diabetes mellitus & $240(38)$ & $66(24)$ & $<0.001$ \\
\hline History of heart failure & $91(14)$ & $31(11)$ & 0.24 \\
\hline Chronic kidney disease & $424(66)$ & $148(53)$ & $<0.001$ \\
\hline \multicolumn{4}{|l|}{ CKD Stage } \\
\hline Mild & 239(37) & 95(35) & 0.0021 \\
\hline Moderate & $288(45)$ & $107(39)$ & $<0.001$ \\
\hline Severe & $38(6)$ & $13(5)$ & 0.028 \\
\hline Bilateral disease ${ }^{* *}$ & $113(22)$ & $58(26)$ & 0.3 \\
\hline \multicolumn{4}{|l|}{ Medication Use } \\
\hline Renin-angiotensin inhibitors & $298(49)$ & $118(49)$ & 0.88 \\
\hline Diuretic & $250(42)$ & $91(37)$ & 0.19 \\
\hline Aldosterone antagonist & $17(3)$ & $9(3)$ & 0.66 \\
\hline$\beta$-Blocker & $319(54)$ & $123(49)$ & 0.18 \\
\hline$\alpha$-Blocker & $102(17)$ & $35(13)$ & 0.19 \\
\hline
\end{tabular}


Table 1. (Continued)

\begin{tabular}{|c|c|c|c|}
\hline Baseline Characteristics* & Non-smoking $(n=654)$ & Smoking $(n=277)$ & P-value \\
\hline$\alpha \beta$-Blocker & $62(10)$ & $31(12)$ & 0.47 \\
\hline Calcium-channel blocker & $239(43)$ & $84(36)$ & 0.057 \\
\hline Renin inhibitor & $6(1)$ & $0(0)$ & 0.19 \\
\hline Vasodilator & $33(5)$ & $10(4)$ & 0.40 \\
\hline Nitrate & $115(19)$ & $55(22)$ & 0.40 \\
\hline Antiplatelet agent & $361(65)$ & $173(75)$ & 0.012 \\
\hline Lipid-lowering agent & $352(68)$ & $138(61)$ & 0.093 \\
\hline Total hypertensive medications & $2.1 \pm 1.5$ & $1.8 \pm 1.5$ & 0.015 \\
\hline Total all medications & $3.4 \pm 2.1$ & $3.2 \pm 2$ & 0.13 \\
\hline
\end{tabular}

*Data are expressed as the mean $\pm S D$ or number (percentage). Comparisons were evaluated using two sample t-test for continuous data or Fisher's exact test with odds ratio for categorical data.

**Bilateral disease was defined as stenosis of $60 \%$ or more of the diameter of at least one artery supplying each kidney.

Abbreviations: $\mathrm{Cl}$, confidence interval; yr, year; in, inch; lb, pound, BMI, body mass index (weight in kilograms divided by the square of the height in meters); BP, blood pressure; MDRD-eGFR, Modification of Diet in Renal Disease-estimated glomerular filtration rate; CKD-EPI, Chronic Kidney Disease Epidemiology Collaboration; and CKD, Chronic kidney disease.

https://doi.org/10.1371/journal.pone.0173562.t001

replacement therapy $(2.11[0.82,5.45] ; \mathrm{p}=0.12)(68 \pm 9.0$ vs $77 \pm 7.8, \mathrm{p}<0.001)$, but the rate of this event was very low.

\section{Longitudinal analysis of smoking effect on renal and cardiovascular function}

After adjusting for age, sex, diabetes, and BMI, there was no difference observed in measures of kidney function including serum creatinine and eGFR (Modified Diet in Renal Disease creatinine-based formula [MDRD-eGFR], Fig 4A and 4B) between smokers and non-smokers.

Urine Albumin-to-Creatinine Ratio (UACR) increased more in smokers than in non-smokers over time and was significant at 3 years post-enrollment (Fig $4 \mathrm{C}, \mathrm{p}<0.05$ ). Cystatin $\mathrm{C}$ was also significantly higher in patients who smoked at baseline and throughout the study period (Fig $4 \mathrm{D}, \mathrm{p}<0.05)$. Similar results were observed in analysis using the Chronic Kidney Disease Epidemiologic Collaboration (CKD-EPI) formulae for creatinine, cystatin C, and GFR combining creatinine and cystatin $\mathrm{C}$ (data not shown).

To further examine the longitudinal effect of smoking on kidney function, the slope of natural $\log$ of eGFR versus time for each individual was obtained by linear regression to account for variable responses among subjects. These slopes were then used as the response variable and fitted into a multivariate regression model with age, sex, ethnicity, smoking, diabetes and BMI as covariates. The plot of predicted slope with $95 \%$ confidence intervals versus age at enrollment grouped by smoking status is shown in Fig 5, which showed a trend of decreased renal function in non-smokers that may be related to their older age, but it failed to reach statistical significance. In addition, hypertension measured by systolic or diastolic blood pressure, and pulse pressure were not significantly different between smokers and non-smokers (Fig 6).

\section{Discussion}

We studied the effects of smoking on cardio-renal outcomes in patients with clinically significant renal artery stenosis and renovascular hypertension. The significant finding is that active smokers presented with renal artery stenosis at a much younger age and experienced cardiorenal events at a younger age than non-smoking participants. Smoking was significantly 
Table 2. Multivariate linear regression and generalized linear regression comparing smokers and non-smokers on baseline characteristics as the response adjusted for age, sex and ethnicity.

\begin{tabular}{|c|c|}
\hline Baseline Characteristics & Smoking: Yes Coefficient (p-value) \\
\hline \multicolumn{2}{|l|}{ Demographic/physical examination } \\
\hline Height (in) & $0.74(<0.002)$ \\
\hline Weight (lb) & $-14.0(<0.001)$ \\
\hline BMI & $-3.00(<0.001)$ \\
\hline Systolic BP (mmHg) & $0.43(0.82)$ \\
\hline Diastolic BP (mmHg) & $-0.22(0.83)$ \\
\hline \multicolumn{2}{|l|}{ Angiographic findings } \\
\hline$\%$ stenosis, assessed by core laboratory & $1.1(0.30)$ \\
\hline$\%$ stenosis, assessed visually & $2.0(<0.05)$ \\
\hline \multicolumn{2}{|c|}{ Laboratory values (assessed by core lab)** } \\
\hline Creatinine (mg/dl) & $0.014(0.71)$ \\
\hline MDRD-eGFR (ml/min per $\left.1.73 \mathrm{~m}^{2}\right)$ & $-0.67(0.72)$ \\
\hline Cystatin C (mg/L) & $0.10(<0.01)$ \\
\hline Potassium (mmol/L) & $0.015(0.21)$ \\
\hline UACR (ug/mg) & $-0.10(0.50)$ \\
\hline \multicolumn{2}{|l|}{ Risk factors/indications } \\
\hline Creatinine $\geq 1.6(\mathrm{mg} / \mathrm{dl})$ & $0.15(0.43)$ \\
\hline Peripheral vascular disease & $1.04(<0.001)$ \\
\hline Hyperlipidemia & $-0.19(0.47)$ \\
\hline Prior myocardial infarction & $0.14(0.42)$ \\
\hline Prior transient ischemic accident & $0.19(0.35)$ \\
\hline Angina & $0.25(0.33)$ \\
\hline Cardiovascular disease & $0.07(0.70)$ \\
\hline Diabetes & $-0.85(<0.001)$ \\
\hline History of heart failure & $-0.34(0.17)$ \\
\hline Chronic kidney disease & $-0.002(0.99)$ \\
\hline Bilateral disease $* * *$ & $0.45(<0.05)$ \\
\hline
\end{tabular}

Linear model was used for continuous data and generalized linear model (GLM) for categorical factors.

** Laboratory values were log transformed when statistical analysis was performed.

*** Bilateral disease was defined as stenosis of $60 \%$ or more of the diameter of at least one artery supplying each kidney.

Abbreviations: in: inch; lb: pound, BMI: body mass index (weight in kilograms divided by the square of the height in meters); BP: blood pressure; MDRD-eGFR: Modification of Diet in Renal Disease-estimated glomerular filtration rate; UACR: urine albumin creatinine ratio (measured as the log UACR).

https://doi.org/10.1371/journal.pone.0173562.t002

associated with cardiovascular or kidney death, myocardial infarction, stroke, hospitalization for congestive heart failure and progressive renal insufficiency. Even though smokers were 9.1 years younger at enrollment, they did not differ from non-smokers in renal artery stenosis severity. This is consistent with the known effect of smoking to accelerate atherosclerosis onset and progression [24-26], and that smoking increases risk for renal artery stenosis [17].

The effect of active smoking on renal function was less clear in the current study. We found no significant difference in renal function over time as evaluated by creatinine or creatininebased eGFR among smokers and non-smokers, however, cystatin C levels were significantly higher in smokers at baseline and throughout follow up. The reason for this divergent finding on renal function estimation is not clear. The creatinine- or cystatin C-based eGFR may not be reliable indicators of renal function in populations who smoke as reported by Yamada [27]. 


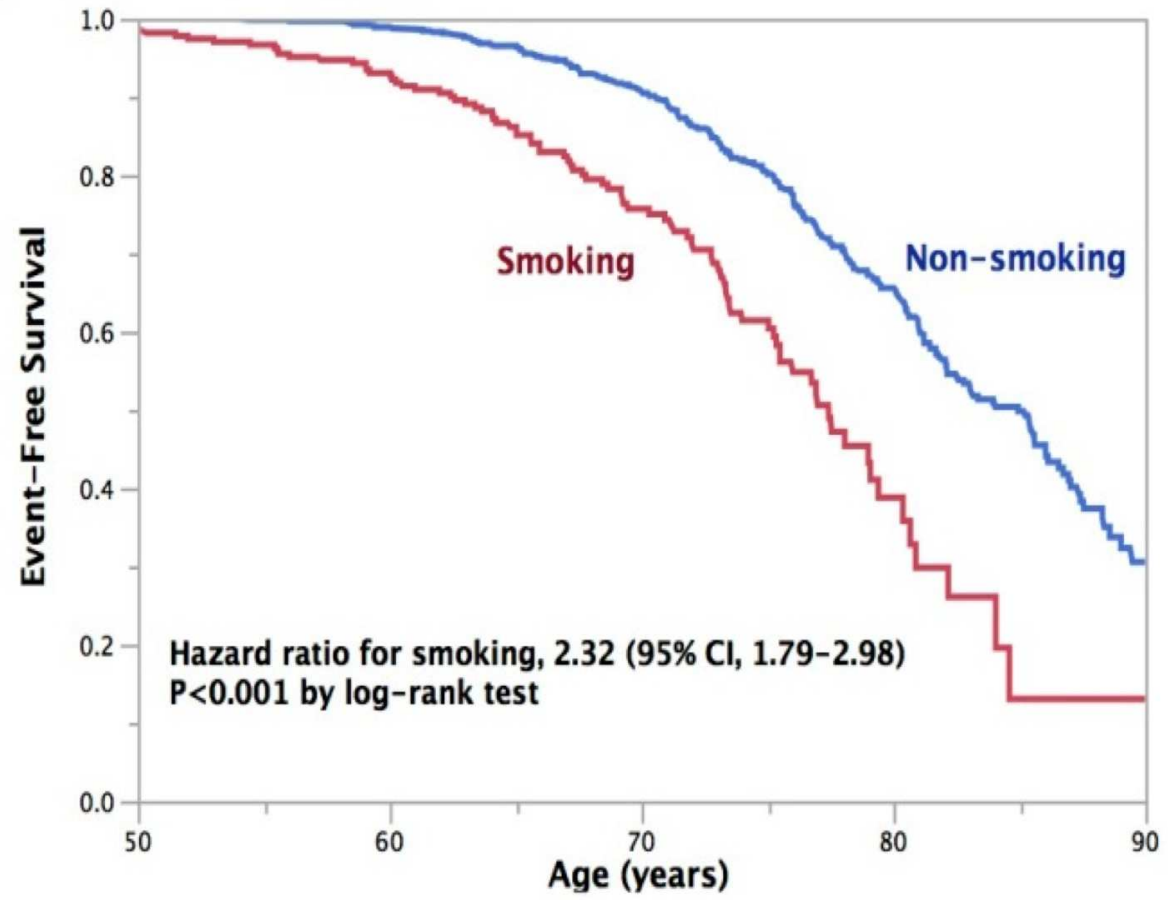

\begin{tabular}{|c|c|c|c|c|c|c|c|c|c|}
\hline \multirow{2}{*}{ Number at risk* } & \multicolumn{10}{|c|}{ Age (years) } \\
\cline { 2 - 10 } & $\mathbf{5 0}$ & $\mathbf{5 5}$ & $\mathbf{6 0}$ & $\mathbf{6 5}$ & $\mathbf{7 0}$ & $\mathbf{7 5}$ & $\mathbf{8 0}$ & $\mathbf{8 5}$ & $\mathbf{9 0}$ \\
\hline Smoking & 277 & 251 & 224 & 172 & 117 & 64 & 16 & 3 & 2 \\
\hline Non-smoking & 644 & 641 & 630 & 586 & 512 & 388 & 232 & 97 & 17 \\
\hline
\end{tabular}

*Smoking status was missing for 10 subjects

Fig 3. Kaplan-Meier curves of event-free survival for age-at-composite endpoint delineated by smoking status. The hazard ratio, assessed by log-rank test for age-at-composite endpoint delineated by smoking status, was $2.32[1.79,2.98], \mathrm{p}<0.001$.

https://doi.org/10.1371/journal.pone.0173562.g003

Other factors beyond renal function can influence serum cystatin C levels [28]. Since cystatin $\mathrm{C}$ could be associated with inflammation [29], the observed increase of cystatin C in smokers

Table 3. Clinical events comparing smokers and non-smokers adjusted for sex, ethnicity and BMI using age-at-event (years) as the response.

\begin{tabular}{|c|c|c|c|}
\hline Clinical Endpoint* & Smoking: Yes & Confidence Interval & P-Value \\
\hline Primary composite endpoint & 2.32 & $(1.79,2.98)$ & $<0.001$ \\
\hline \multicolumn{4}{|l|}{ Secondary clinical endpoints** } \\
\hline Cardiovascular or renal death & 1.77 & $(1.02,3.05)$ & 0.04 \\
\hline Myocardial infarction & 1.82 & $(1.06,3.13)$ & 0.03 \\
\hline Stroke & 2.59 & $(1.27,5.27)$ & 0.01 \\
\hline Hospitalization for congestive heart failure & 2.03 & $(1.17,3.52)$ & 0.01 \\
\hline Progressive renal insufficiency & 2.38 & $(1.68,3.38)$ & $<0.001$ \\
\hline Permanent renal replacement therapy & 2.11 & $(0.82,5.45)$ & 0.12 \\
\hline
\end{tabular}

* Rows display the hazard ratio, 95\% confidence interval and p-value calculated using multivariable Cox proportional-hazards regression including DBP, peripheral vascular disease, and antihypertensive treatment. The multivariable, adjusted factors, and interaction term in the model were not significant except for smoking which is reported.

**Each component of the primary endpoint is included for the occurrence of the event. 
a

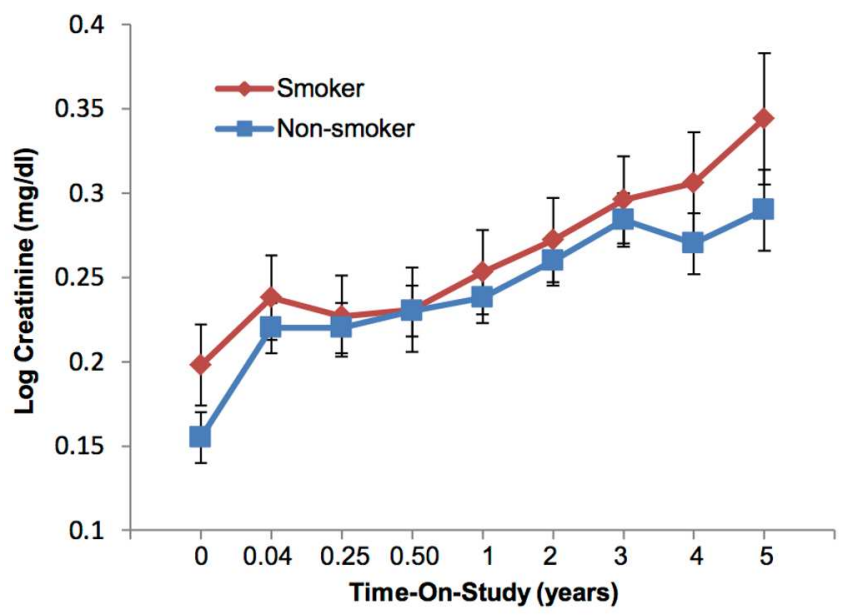

C

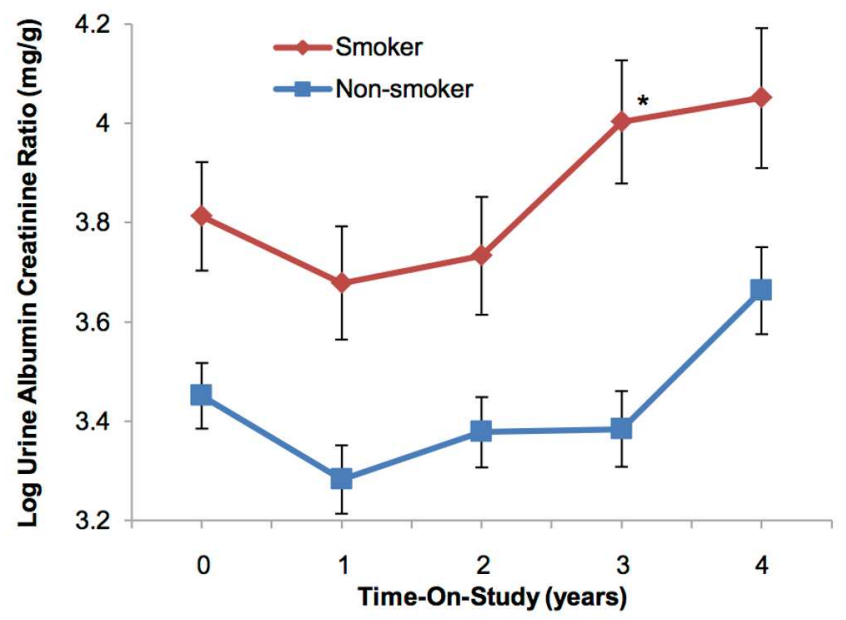

b

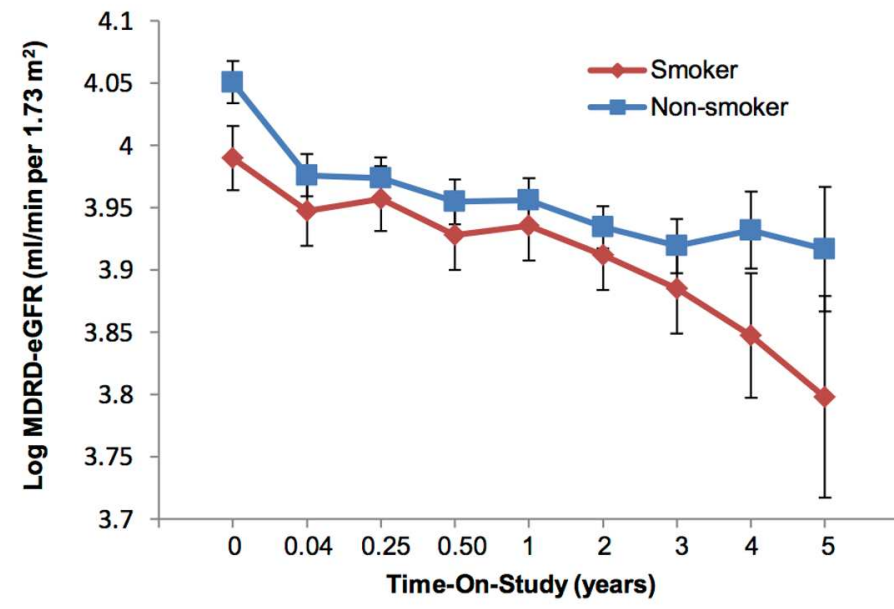

d

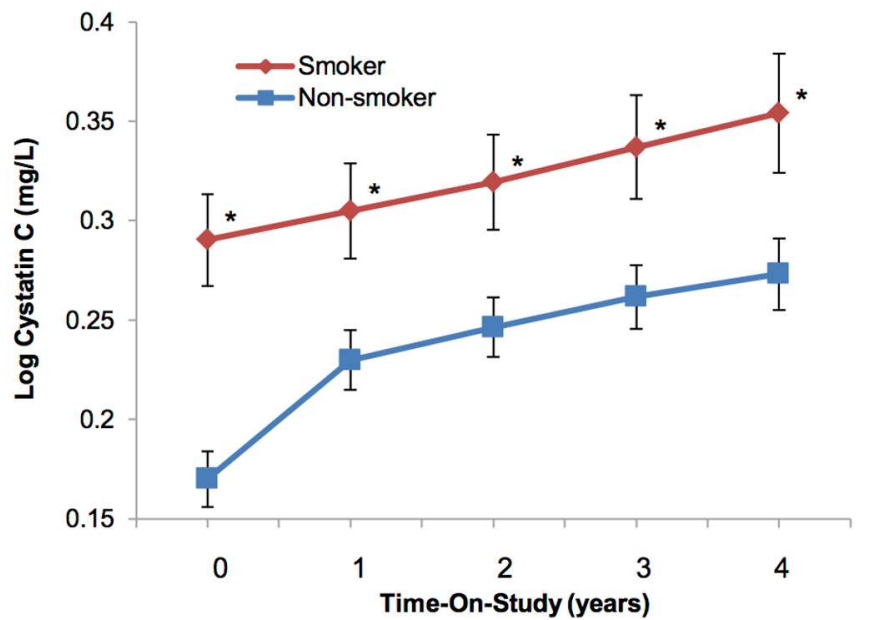

Fig 4. Longitudinal analysis of the effect of smoking on kidney function. Least square means measured over time-in-study are delineated by smoking status, and the panels display the following: a): log values of the means for creatinine (mg/dL); $b$ ): log values of the means for MDRD-eGFR (mL/min per $\left.\left.1.73 \mathrm{~m}^{2}\right) ; \mathrm{c}\right)$ : $\log$ values of the means for Urine Albumin to Creatinine Ratio (mg/g); and d): log values of the means for Cystatin C (mg/L). An asterisk ( ${ }^{*}$ ) indicates the mean for smokers is significantly different than non-smokers value at same time point $(p<0.05)$.

https://doi.org/10.1371/journal.pone.0173562.g004

could be due to the smoking induced inflammation. In addition, plasma creatinine level is dependent of tissue mass and BMI. The age as well as BMI in the smokers in this study is significantly different from the non-smokers. Therefore, we adjusted the age and BMI in our regression analysis in Table 2 . It is also not clear whether smoking has any direct effect on plasma creatinine levels. It would prudent to consider these effects when assessing renal functions in smoking populations.

Other studies have found a relationship between smoking and kidney diseases including IgA glomerulonephritis or autosomal dominant polycystic kidney disease [3]. In the Multiple Risk Factor Intervention Trial (MRFIT) smoking was associated with an increased risk for ESRD and chronic kidney disease (CKD) [30]. This is supported by several other populationbased longitudinal studies from countries including the United States, Japan, and Australia 


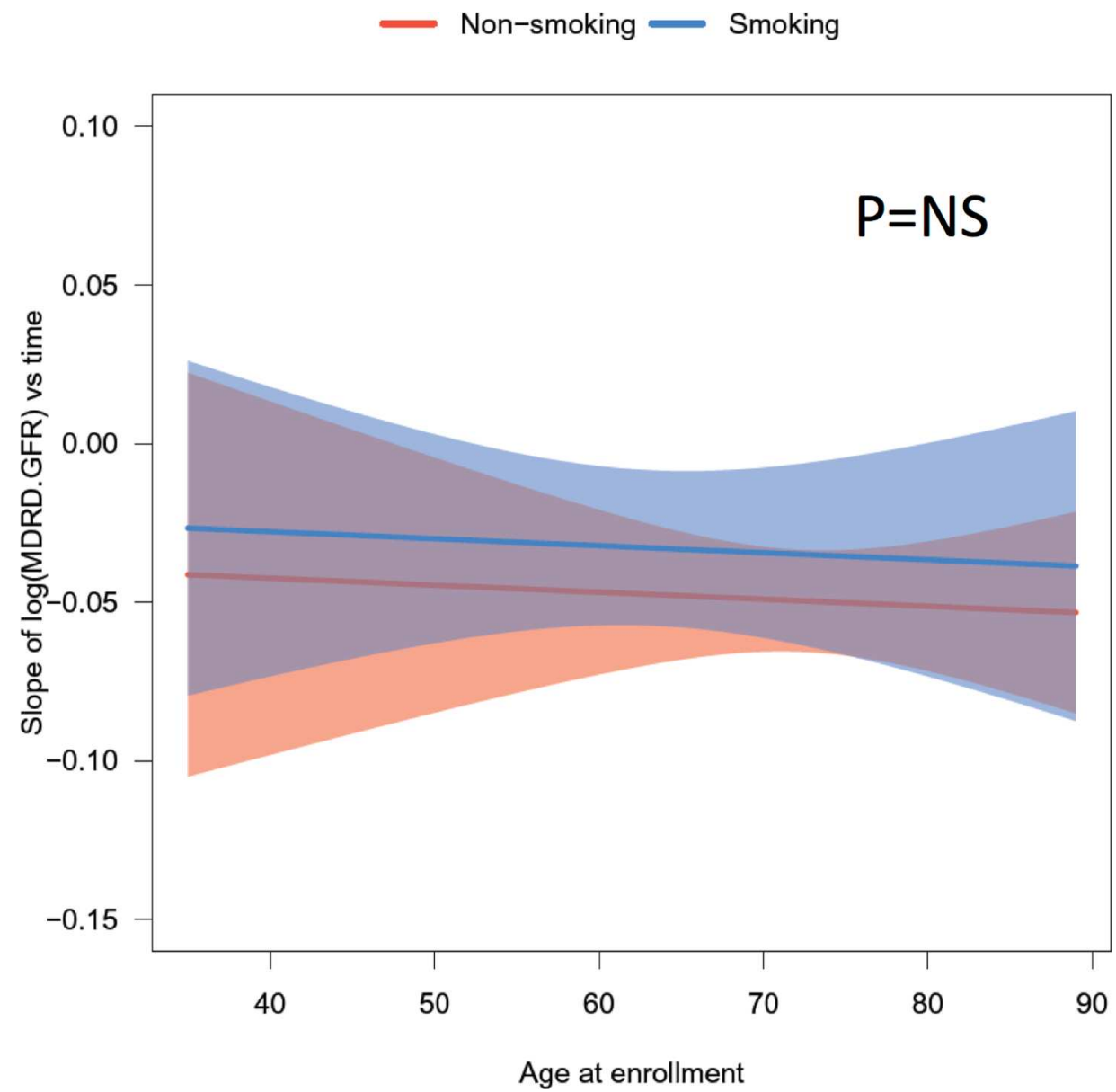

Fig 5. Fitted longitudinal slope of the natural log of MDRD-GFR over time-in-study by age at enrollment. For each individual, the longitudinal slope of MDRD-GFR was obtained by linear regression between the log of MDRD-GFR and time-in-study for that patient. These slopes were used as the response variable and fitted into a multiple variable regression model with age, sex, ethnicity, smoking, diabetes and $\mathrm{BMI}$ as covariates. The plot of the predicted slope of MDRD-GFR over time with $95 \%$ confidence intervals was generated for age at enrollment grouped by smoking status (red for smokers and blue for non-smokers).

https://doi.org/10.1371/journal.pone.0173562.g005

with enrollments ranging between 11,247 to over 100,000 individuals [6, 9, 31-34]. The PREVEND trial found a correlation between urine albumin excretion, a marker of kidney damage, and cigarette smoking $[4-6,8,9,35]$. Yoon et al. found that smokers from the general population with a GFR $\geq 50 \mathrm{~mL} / \mathrm{min}$ had less deterioration of kidney function but a higher risk of proteinuria, while in those with reduced GFR $(<50 \mathrm{~mL} / \mathrm{min})$ smoking was associated with a decline in GFR [36].

In the current study we only collected information on active smoking status and thus were unable to distinguish former smokers from participants who have never smoked, and did not have information on pack years and daily usage at baseline or through follow-up. This is a common issue for studies of this type [36-41]. While more detailed data on daily smoking consumption and cumulative pack years may assist to further refine the outcomes of this study, the overall findings remain important given the marked differences in outcomes between smokers and non-smokers.

In summary, the current study demonstrated that active smoking results in clinical significant renal artery stenosis, and adverse cardio-renal events, at much younger age. It also clearly 
a

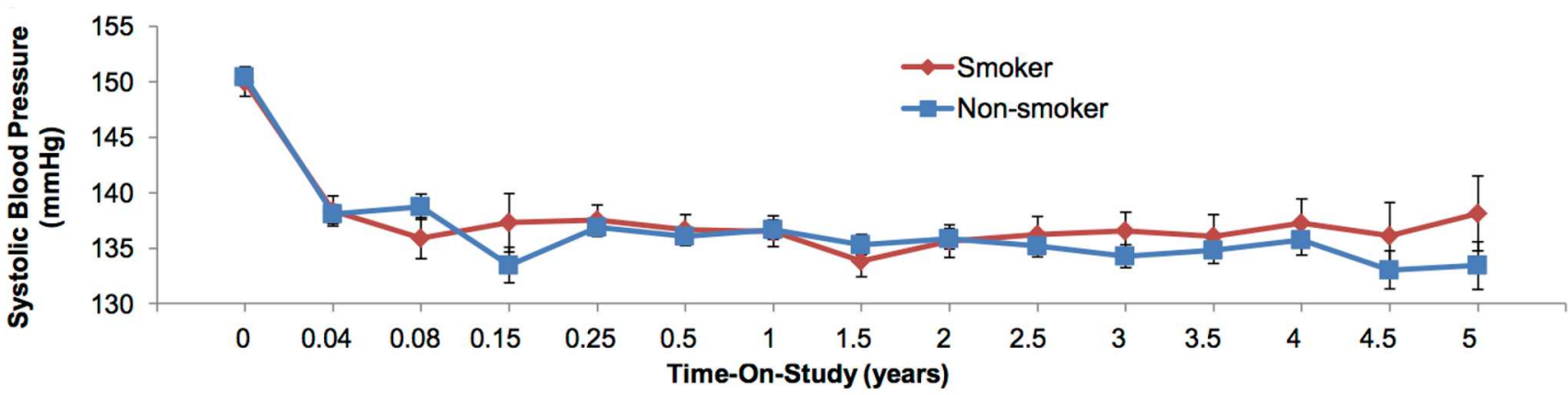

b
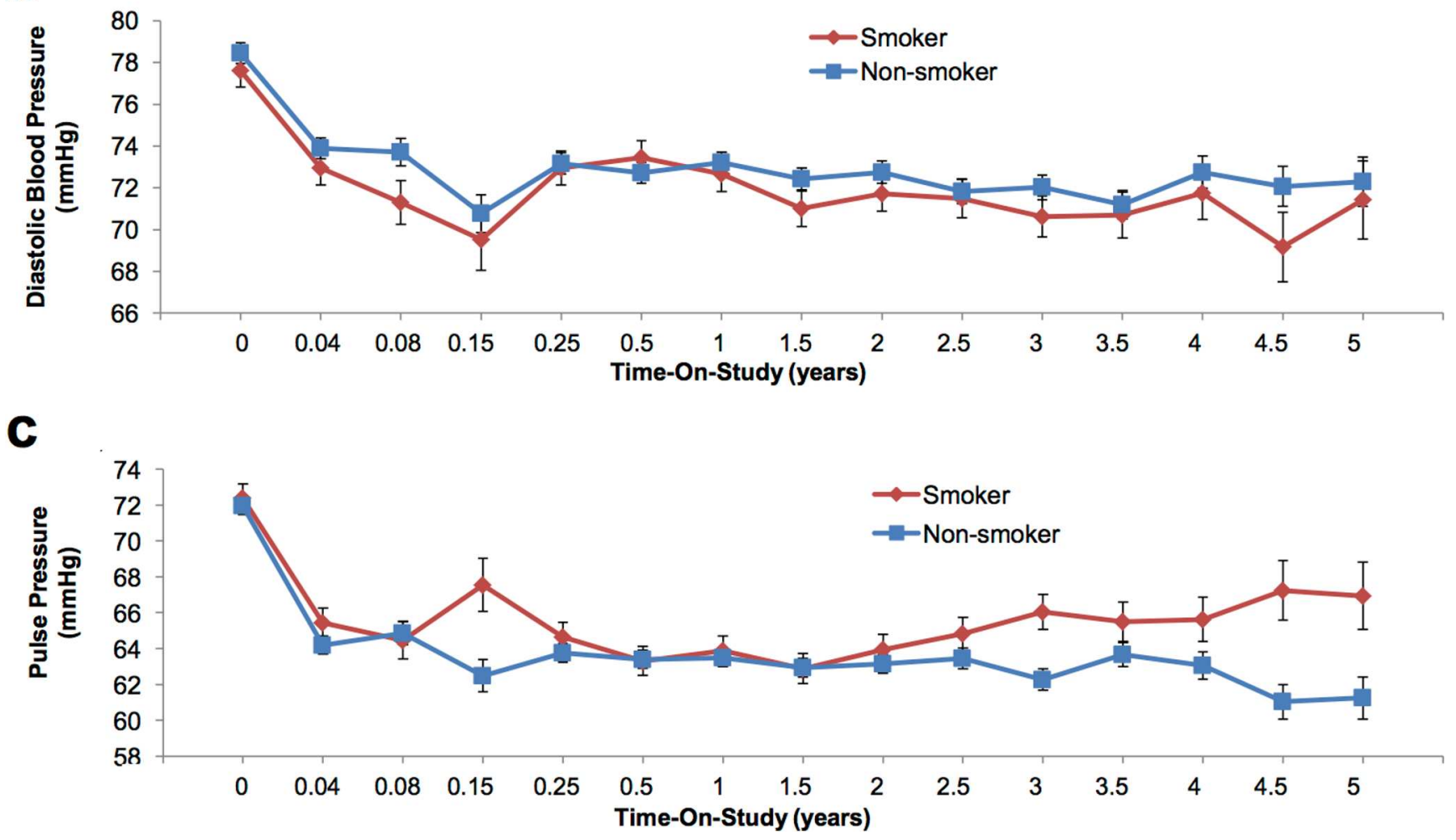

Fig 6. Longitudinal effect on blood pressure for smokers versus non-smokers. Graphs represent the following: a): systolic blood pressure $(\mathrm{mmHg}) ; \mathrm{b})$ : diastolic blood pressure $(\mathrm{mmHg})$; and c): pulse pressure $(\mathrm{mmHg})$. Mean $\pm \mathrm{SD}$ for the patient data from baseline through follow-up are given. No significant differences were observed.

https://doi.org/10.1371/journal.pone.0173562.g006

indicates that smoking increases the risk of deadly consequences in patients with renovascular hypertension and indicate a need for cessation counseling for patients that currently smoke.

\section{Author Contributions}

Conceptualization: CJC JT LDD.

Formal analysis: PSB WH KR YX.

Funding acquisition: CJC.

Investigation: CJC CAD PSB JT. 
Methodology: PSB CJC WH CAD.

Project administration: CJC JT.

Supervision: CJC.

Validation: PSB CJC.

Writing - original draft: JT CAD PSB STH.

Writing - review \& editing: CJC LDD JIS KRT KJ DEC TPM RBD WLH.

\section{References}

1. Centers for Disease $C$, Prevention. Smoking-attributable mortality, years of potential life lost, and productivity losses_-United States, 2000-2004. MMWR Morbidity and mortality weekly report. 2008; 57 (45):1226-8. Epub 2008/11/15. PMID: 19008791

2. Mokdad AH, Marks JS, Stroup DF, Gerberding JL. Actual causes of death in the United States, 2000. JAMA: the journal of the American Medical Association. 2004; 291(10):1238-45. Epub 2004/03/11. https://doi.org/10.1001/jama.291.10.1238 PMID: 15010446

3. Orth SR, Stockmann A, Conradt C, Ritz E, Ferro M, Kreusser W, et al. Smoking as a risk factor for endstage renal failure in men with primary renal disease. Kidney international. 1998; 54(3):926-31. Epub 1998/09/12. https://doi.org/10.1046/j.1523-1755.1998.00067.x PMID: 9734618

4. Orth SR. Smoking and the Kidney. Journal of the American Society of Nephrology. 2002; 13(6):166372. PMID: 12039997

5. Orth SR. Cigarette smoking: an important renal risk factor-far beyond carcinogenesis. Tobacco induced diseases. 2002; 1(2):137-55. Epub 2002/01/01. PubMed Central PMCID: PMCPMC2671650. https://doi.org/10.1186/1617-9625-1-2-137 PMID: 19570254

6. Orth SR, Hallan SI. Smoking: A Risk Factor for Progression of Chronic Kidney Disease and for Cardiovascular Morbidity and Mortality in Renal Patients-Absence of Evidence or Evidence of Absence? Clinical Journal of the American Society of Nephrology. 2008; 3(1):226-36. https://doi.org/10.2215/ CJN.03740907 PMID: 18003763

7. Harding MB, Smith LR, Himmelstein SI, Harrison K, Phillips HR, Schwab SJ, et al. Renal artery stenosis: prevalence and associated risk factors in patients undergoing routine cardiac catheterization. J Am Soc Nephrol. 1992; 2(11):1608-16. Epub 1992/05/01. PMID: 1610982

8. Orth SR. Effects of Smoking on Systemic and Intrarenal Hemodynamics: Influence on Renal Function. Journal of the American Society of Nephrology. 2004; 15(1 suppl):S58-S63.

9. Halimi JM, Giraudeau B, Vol S, Caces E, Nivet H, Lebranchu Y, et al. Effects of current smoking and smoking discontinuation on renal function and proteinuria in the general population. Kidney international. 2000; 58(3):1285-92. Epub 2000/09/06. https://doi.org/10.1046/j.1523-1755.2000.00284.x PMID: 10972692

10. Altay S, Onat A, Ozpamuk-Karadeniz F, Karadeniz Y, Kemaloglu-Oz T, Can G. Renal "hyperfiltrators" are at elevated risk of death and chronic diseases. BMC nephrology. 2014; 15(1):160. Epub 2014/10/04.

11. Yamagata $K$, Ishida $K$, Sairenchi $T$, Takahashi $H$, Ohba S, Shiigai $T$, et al. Risk factors for chronic kidney disease in a community-based population: a 10-year follow-up study. Kidney international. 2007; 71 (2):159-66. https://doi.org/10.1038/sj.ki.5002017 PMID: 17136030

12. Derkx FH, Schalekamp MA. Renal artery stenosis and hypertension. Lancet. 1994; 344(8917):237-9. Epub 1994/07/23. PMID: 7913161

13. Ram CV. Renovascular hypertension. Curr Opin Nephrol Hypertens. 1997; 6(6):575-9. Epub 1998/02/ 12. PMID: 9375273

14. Vokonas PS, Kannel WB, Cupples LA. Epidemiology and risk of hypertension in the elderly: the Framingham Study. J Hypertens Suppl. 1988; 6(1):S3-9. Epub 1988/11/01. PMID: 3216240

15. Textor SC. Atherosclerotic Renal Artery Stenosis: Flaws in Estimated Glomerular Filtration Rate and the Problem of Progressive Kidney Injury. Circulation: Cardiovascular Interventions. 2011; 4(3):213-5.

16. Kennedy DJ, Colyer WR, Brewster PS, Ankenbrandt M, Burket MW, Nemeth AS, et al. Renal insufficiency as a predictor of adverse events and mortality after renal artery stent placement. American journal of kidney diseases: the official journal of the National Kidney Foundation. 2003; 42(5):926-35.

17. Mackay A, Brown JJ, Cumming AM, Isles C, Lever AF, Robertson JI. Smoking and renal artery stenosis. British medical journal. 1979; 2(6193):770. Epub 1979/09/29. PubMed Central PMCID: PMC1596397. PMID: 519191 
18. Cooper CJ, Murphy TP, Cutlip DE, Jamerson K, Henrich W, Reid DM, et al. Stenting and medical therapy for atherosclerotic renal-artery stenosis. The New England journal of medicine. 2014; 370(1):1322. Epub 2013/11/20. https://doi.org/10.1056/NEJMoa1310753 PMID: 24245566

19. Levey AS, Inker LA, Matsushita K, Greene T, Willis K, Lewis E, et al. GFR decline as an end point for clinical trials in CKD: a scientific workshop sponsored by the National Kidney Foundation and the US Food and Drug Administration. American journal of kidney diseases: the official journal of the National Kidney Foundation. 2014; 64(6):821-35. Epub 2014/12/03.

20. Thiebaut AC, Benichou J. Choice of time-scale in Cox's model analysis of epidemiologic cohort data: a simulation study. Statistics in medicine. 2004; 23(24):3803-20. Epub 2004/12/08. https://doi.org/10. 1002/sim.2098 PMID: 15580597

21. Commenges $D$, Letenneur $L$, Joly $P$, Alioum $A$, Dartigues JF. Modelling age-specific risk: application to dementia. Statistics in medicine. 1998; 17(17):1973-88. PMID: 9777690

22. Korn EL, Graubard BI, Midthune D. Time-to-event analysis of longitudinal follow-up of a survey: choice of the time-scale. Am J Epidemiol. 1997; 145(1):72-80. PMID: 8982025

23. Duchesne T, Lawless J. Alternative time scales and failure time models. Lifetime Data Anal. 2000; 6 (2):157-79. PMID: 10851840

24. Puri R, Nissen SE, Shao M, Ballantyne CM, Barter PJ, Chapman MJ, et al. Antiatherosclerotic Effects of Long-Term Maximally Intensive Statin Therapy After Acute Coronary Syndrome: Insights From Study of Coronary Atheroma by Intravascular Ultrasound: Effect of Rosuvastatin Versus Atorvastatin. Arteriosclerosis, thrombosis, and vascular biology. 2014; 34(11):2465-72. Epub 2014/09/13. https:// doi.org/10.1161/ATVBAHA.114.303932 PMID: 25212234

25. Cheng S, Claggett B, Correia AW, Shah AM, Gupta DK, Skali H, et al. Temporal trends in the population attributable risk for cardiovascular disease: the atherosclerosis risk in communities study. Circulation. 2014; 130(10):820-8. Epub 2014/09/12. PubMed Central PMCID: PMCPmc4161984. https://doi.org/ 10.1161/CIRCULATIONAHA.113.008506 PMID: 25210095

26. Malerba M, Montuschi P, Radaeli A, Pirisi M. Role of beta-blockers in patients with COPD: current perspective. Drug discovery today. 2015; 20(1):129-35. Epub 2014/09/23. https://doi.org/10.1016/j.drudis. 2014.09.005 PMID: 25238736

27. Yamada $Y$, Noborisaka $Y$, Ishizaki M, Yamazaki M, Honda R, Yokoyama H, et al. Different association of cigarette smoking with GFR estimated from serum creatinine and that from serum cystatin $\mathrm{C}$ in the general population. Clinical and experimental nephrology. 2015; 19(4):669-77. https://doi.org/10.1007/ s10157-014-1058-y PMID: 25407760

28. Knight EL, Verhave JC, Spiegelman D, Hillege HL, de Zeeuw D, Curhan GC, et al. Factors influencing serum cystatin $C$ levels other than renal function and the impact on renal function measurement. Kidney international. 2004; 65(4):1416-21. https://doi.org/10.1111/j.1523-1755.2004.00517.x PMID: 15086483

29. Okura T, Jotoku M, Irita J, Enomoto D, Nagao T, Desilva VR, et al. Association between cystatin C and inflammation in patients with essential hypertension. Clinical and experimental nephrology. 2010; 14 (6):584-8. https://doi.org/10.1007/s10157-010-0334-8 PMID: 20809110

30. Klag MJ, Whelton PK, Randall BL, Neaton JD, Brancati FL, Ford CE, et al. Blood pressure and endstage renal disease in men. The New England journal of medicine. 1996; 334(1):13-8. Epub 1996/01/ 04. https://doi.org/10.1056/NEJM199601043340103 PMID: 7494564

31. Ritz E. Smoking and the kidney. In: Broe M, Porter G, Bennett W, Deray G, editors. Clinical Nephrotoxins: Springer US; 2008. p. 895-900.

32. Haroun MK, Jaar BG, Hoffman SC, Comstock GW, Klag MJ, Coresh J. Risk factors for chronic kidney disease: a prospective study of 23,534 men and women in Washington County, Maryland. J Am Soc Nephrol. 2003; 14(11):2934-41. Epub 2003/10/22. PMID: 14569104

33. Briganti EM, Branley P, Chadban SJ, Shaw JE, McNeil JJ, Welborn TA, et al. Smoking is associated with renal impairment and proteinuria in the normal population: the AusDiab kidney study. Australian Diabetes, Obesity and Lifestyle Study. American journal of kidney diseases: the official journal of the National Kidney Foundation. 2002; 40(4):704-12. Epub 2002/09/27.

34. Wong CW, Wong TY, Cheng CY, Sabanayagam C. Kidney and eye diseases: common risk factors, etiological mechanisms, and pathways. Kidney international. 2014; 85(6):1290-302. https://doi.org/10. 1038/ki.2013.491 PMID: 24336029

35. Pinto-Sietsma SJ, Mulder J, Janssen WM, Hillege HL, de Zeeuw D, de Jong PE. Smoking is related to albuminuria and abnormal renal function in nondiabetic persons. Annals of internal medicine. 2000; 133 (8):585-91. Epub 2000/10/18. PMID: 11033585

36. Yoon HJ, Park M, Yoon H, Son KY, Cho B, Kim S. The differential effect of cigarette smoking on glomerular filtration rate and proteinuria in an apparently healthy population. Hypertension research: official journal of the Japanese Society of Hypertension. 2009; 32(3):214-9. Epub 2009/03/06. 
37. Noborisaka Y. Smoking and chronic kidney disease in healthy populations. Nephro-urology monthly. 2013; 5(1):655-67. Epub 2013/04/12. PubMed Central PMCID: PMCPmc3614318. https://doi.org/10. 5812/numonthly.3527 PMID: 23577327

38. Ishizaka N, Ishizaka Y, Toda E, Shimomura H, Koike K, Seki G, et al. Association between cigarette smoking and chronic kidney disease in Japanese men. Hypertension research: official journal of the Japanese Society of Hypertension. 2008; 31(3):485-92. Epub 2008/05/24.

39. Sauriasari R, Sakano N, Wang DH, Takaki J, Takemoto K, Wang B, et al. C-reactive protein is associated with cigarette smoking-induced hyperfiltration and proteinuria in an apparently healthy population. Hypertension research: official journal of the Japanese Society of Hypertension. 2010; 33(11):1129-36. Epub 2010/08/13.

40. Miyatake N, Moriyasu H, Sakano N, Tada S, Suzue T, Hirao T. Influence of cigarette smoking on estimated glomerular filtration rate (eGFR) in Japanese male workers. Acta medica Okayama. 2010; 64 (6):385-90. Epub 2010/12/22. PMID: 21173808

41. Noborisaka $Y$, Honda R, Ishizaki M, Nakata M, Yamada Y. Alcohol and cigarette consumption, renal function and blood pressure in middle-aged healthy men. Journal of human hypertension. 2007; 21 (12):966-8. Epub 2007/06/08. https://doi.org/10.1038/sj.jhh.1002242 PMID: 17554344 